\title{
In situ Phase Transition of Elastin-like Polypeptide Chains Regulates Thermo- Responsive Properties of Elastomeric Protein-Based Hydrogels
}

Tianyu Duan and Hongbin Li*

\section{Supplementary Information}

Full amino acid sequences of $(\mathrm{GR})_{4}$ and $\mathrm{Vn}-(\mathrm{GR})_{4}$ proteins. The sequence of GB1 is colored in black, resilin in green and ELP in blue. The underlined sequence are linkers resulting from the restriction enzyme sequences used in the cloning.

$(\mathrm{GR})_{4}$ sequence:

MVDGGS(MDTYKLILNGKTLKGETTTEAVDAATAEKVFKQYANDNGVDGEWTYDDAT KTFTVTE $\underline{R S G G R P S D S Y G A P G G G N} \underline{R S})_{4}$ GGTELKLAAALEHHHHHH

V24-(GR) 4 sequence:

MG(VPGVG) ${ }_{24}$ GS(MDTYKLILNGKTLKGETTTEAVDAATAEKVFKQYANDNGVDGEWT

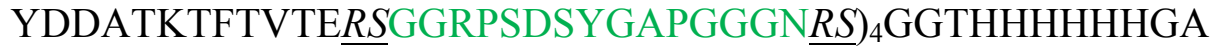

V48-(GR) 4 sequence:

MG(VPGVG) ${ }_{48}$ GS(MDTYKLILNGKTLKGETTTEAVDAATAEKVFKQYANDNGVDGEWT YDDATKTFTVTE $\underline{R S G G R P S D S Y G A P G G G N} \underline{R S})_{4}$ GGTHHHHHHGA

V72-(GR) 4 sequence:

MG(VPGVG) ${ }_{72}$ GS(MDTYKLILNGKTLKGETTTEAVDAATAEKVFKQYANDNGVDGEWT

YDDATKTFTVTE $\underline{R S G G R P S D S Y G A P G G G N} \underline{R S})_{4}$ GGTHHHHHHGA 
Table S1 Theoretical $T_{t}$ of un-fused Vn-ELPs.

\begin{tabular}{ccc}
\hline Chain length $\mathrm{n}$ & Concentration $(\mathrm{mM})$ & $\begin{array}{c}\text { Predicted } \\
\mathrm{T}_{\mathrm{t}}\left({ }^{\circ} \mathrm{C}\right)\end{array}$ \\
\hline 24 & 0.1 & 50.5 \\
& 1.0 & 38.1 \\
\hline 48 & 0.1 & 35.6 \\
& 1.0 & 29.5 \\
\hline 72 & 0.1 & 30.7 \\
& 1.0 & 26.6 \\
\hline
\end{tabular}

The predicted values are calculated by the empirical equation by Meyer and Chilkoti:

$$
T_{t}=T_{t, c}+\frac{k}{L} \ln \left(\frac{C_{c}}{C}\right),
$$

( $\mathrm{L}$ is the chain length in pentapeptides, $\mathrm{C}$ the concentration in $\mu \mathrm{M}, \mathrm{T}_{\mathrm{t}, \mathrm{c}}$ the critical temperature $20.8 \pm 0.3{ }^{\circ} \mathrm{C}, \mathrm{k}$ the constant $129 \pm 3{ }^{\circ} \mathrm{C}$, and $\mathrm{C}_{\mathrm{c}}$ the critical concentration $25000 \pm 4600 \mu \mathrm{M}$ ) 


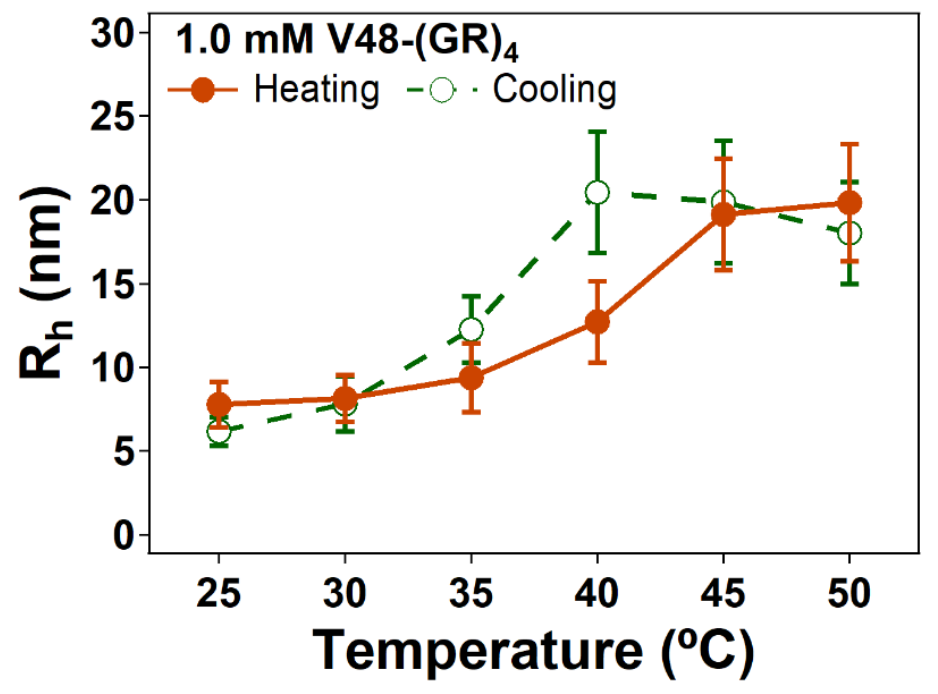

Figure S1. Temperature-dependent $\mathrm{R}_{\mathrm{h}}$ of V48-(GR $)_{4}$ in one heating-cooling cycle between 25 and $50{ }^{\circ} \mathrm{C}$ indicate micellization of V48-YR is reversible. DLS data was collected at $90^{\circ}$ in PBS at 1.0 $\mathrm{mM}$. 

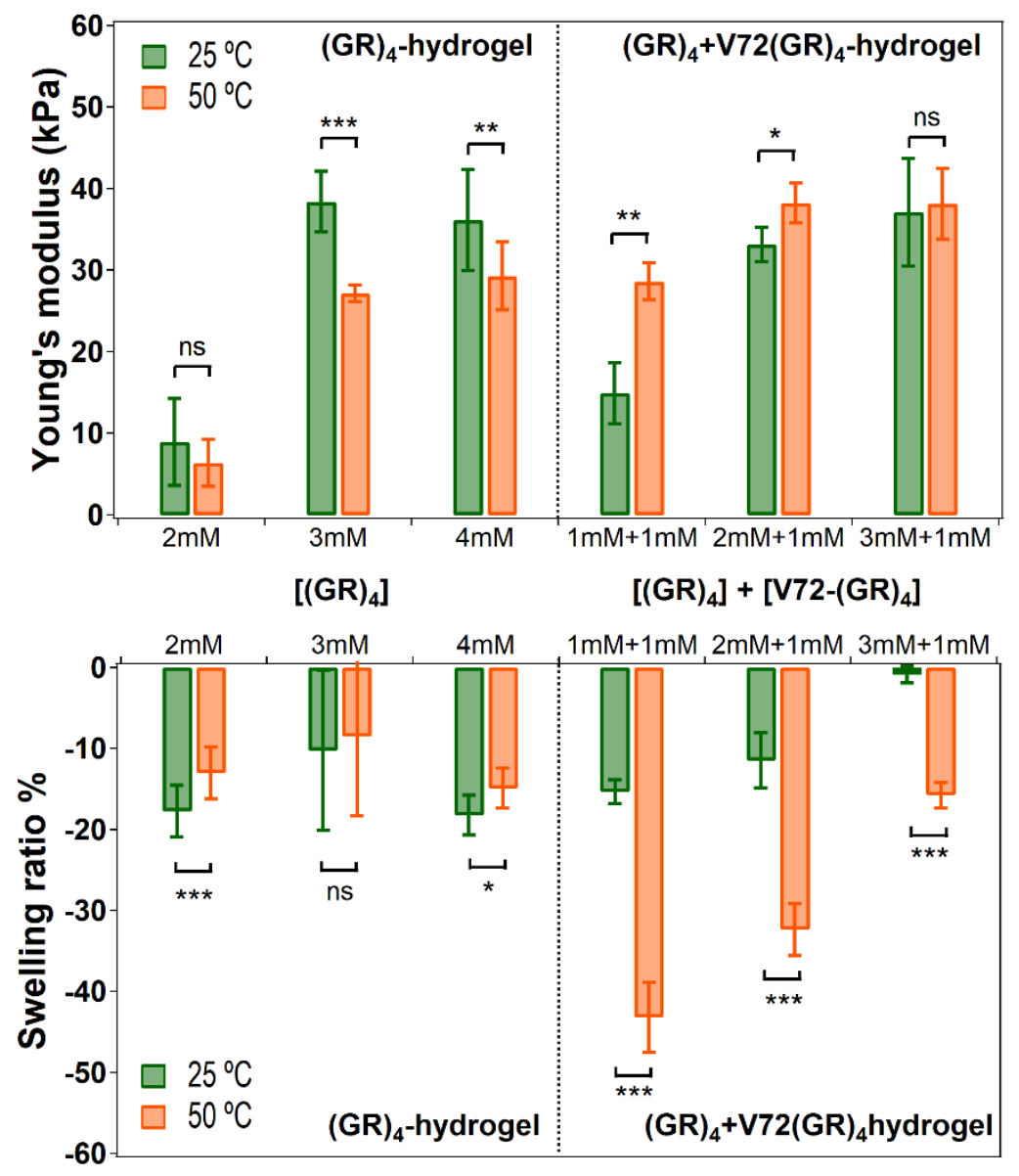

Figure S2. Young's modulus $(\mathrm{n} \geq 3)$ and swelling ratio $(\mathrm{n} \geq 6)$ comparison of $(\mathrm{GR})_{4}$ and $(\mathrm{GR})_{4}+\mathrm{V} 72-(\mathrm{GR})_{4}$-hydrogels with different compositions. All data for comparison are collected in the first heating-cooling cycles. 

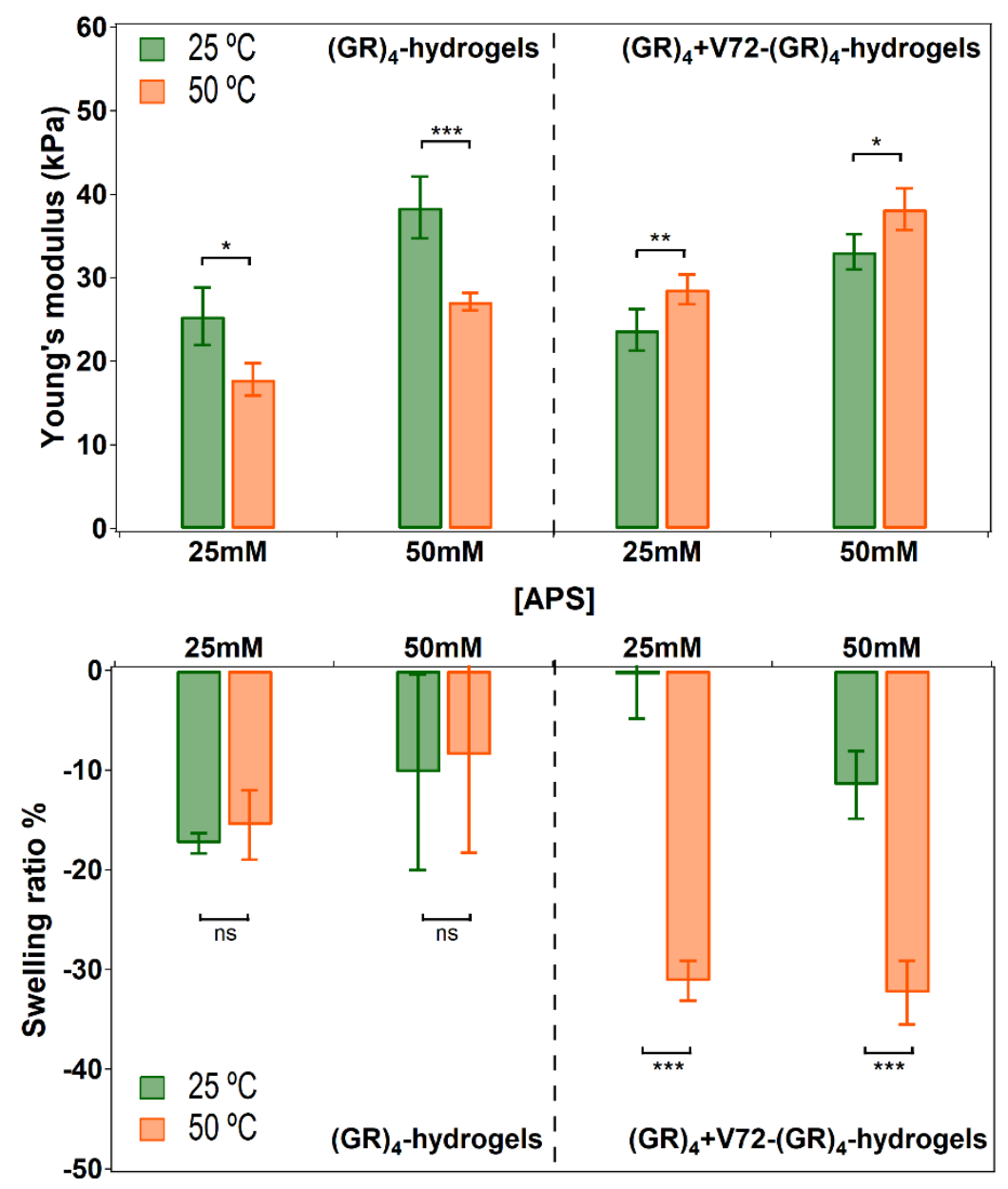

Figure S3. Young's modulus $(\mathrm{n} \geq 3)$ and swelling ratio $(\mathrm{n} \geq 6)$ comparison of $(\mathrm{GR})_{4}$ and $(\mathrm{GR})_{4}+\mathrm{V} 72-(\mathrm{GR})_{4}$-hydrogels prepared with different APS concentrations. The (GR) $)_{4}$-hydrogels are prepared from $3 \mathrm{mM}(\mathrm{GR})_{4}$ solution in PBS,

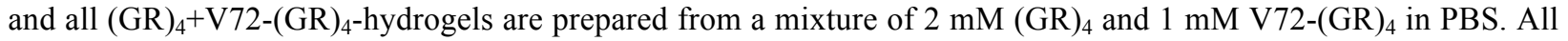
data for comparison are collected in the first heating-cooling cycles. 